\title{
RELIGIÃO: PARA ALÉM DA ACESSIBILIDADE DE UMA EXPERIÊNCIA ARCAICA $^{1}$
}

José Pedro Luchi (Ufes) ${ }^{2}$

luchi-jp@hotmail.com

Resumo: Este artigo reconstrói a hipótese de Habermas de que, no complexo sacral, o rito precede o mito e isso explicaria a permanência da religião como fonte arcaica de solidariedade mesmo no contexto do mundo secular. As narrativas míticas, no confronto com a ciência, vão perdendo a capacidade de explicar o mundo, enquanto os rituais religiosos continuam aptos a produzir integração social e a colaborar para a construção de identidades, ao menos para as pessoas que manifestam tal sensibilidade. É estabelecido um confronto com as posições de Charles Taylor, não diretamente sobre a hipótese acima mencionada, mas sobre os pressupostos que a inspiram. Taylor vê a experiência religiosa como gerada no presente, uma abertura à transcendência do interno da moderna ordem imanente, capaz de oferecer terapia às patologias de uma modernidade que, embora tendo realizado grandes avanços, corre o risco de autoencapsulamento.

Palavras-chave: Rito; Mito; Solidariedade social; Individualização.

\section{INTRODUÇÃO}

Buscando compreender a sobrevivência das tradições religiosas em meio à sociedade que surgiu com a modernidade, Habermas investiga, de um ponto de vista da sociologia e da antropologia cultural, aquilo que, a seu ver, é típico das tradições religiosas, a saber: o complexo sacral, a vinculação

\footnotetext{
${ }^{1}$ Recebido: 04-10-2015/Aceito: 02-03-2016/Publicado on-line: 06-03-2016.

${ }^{2}$ José Pedro Luchi é Professor Associado da Universidade Federal do Espírito Santo, Vitória, ES, Brasil.
} 
entre rito e mito. $\mathrm{O}$ rito, porém, representaria um nível mais antigo de comunicação e os significados nele encerrados estabilizariam as conexões sociais com sentido próprio, independente das conexões narrativas. Revisitando as contribuições de pensadores relevantes para o tema, sobretudo Durkheim, são entrecruzadas teoricamente as funções da práxis ritual, de renovação da solidariedade social e da conservação da identidade, de um lado, com as crises evolucionárias do processo do conhecimento do mundo e da coordenação social das ações, de outro lado. Primordial nas tradições religiosas seria, então, a práxis ritual, que representa uma experiência arcaica geradora de solidariedade social renovada em meio às cisões e tensões entre novos níveis de socialização e individualização, à qual, então, as pessoas religiosas de nosso tempo ainda teriam acesso.

Percorremos o itinerário da construção habermasiana de uma hipótese antropológico-sociológica a respeito da origem do rito, como resposta à necessidade de identidade e integração grupal no momento da passagem evolutiva da comunicação por gestos à comunicação simbólica. No quadro do complexo sacral, composto por rito e mito, Habermas encontra razões para dar primazia genética ao rito e vê o mito como narrativa explicitadora do sentido do rito.

Mesmo quando, com o advento de novos conhecimentos sobre o mundo e no contexto científico da modernidade, o mito deve ser modificado ou não se sustenta mais como explicação cognitiva do mundo, o rito ainda se mantém na sua função de autorreferência coletiva e possibilidade de renovação da pertença. As pessoas de sensibilidade religiosa manteriam o acesso a tal fonte celebrativa de solidariedade, uma experiência propriamente 
arcaica, mas que permanece opcionalmente aberta aos crentes. Não pode pretender constituir um caminho racionalmente obrigatório e necessário, mas continua uma fonte possível de recursos integrativos e terapêuticos.

Com tal hipótese, Habermas pretende tornar compreensível a continuidade de um significativo contingente de cidadãos religiosos na sociedade contemporânea e mesmo a sua revitalização, situação e tendência contrária às expectativas de boa parte da Academia.

Confrontamos essa posição reservada de Habermas com aquela de Charles Taylor. Por que Taylor? Porque ambos se movem no mesmo campo de problemas, como reconhece seu oponente, e tiveram debates explícitos sobre o tema da religião, como registra o volume publicado por Mendieta e Vanantwerpen (2012). O autor canadense reconstrói a gênese da "ordem imanente" do mundo atual, onde as diversas instâncias e instituições não apelam a Deus para sua legitimidade. Porém diagnostica possibilidades não apenas arcaicas para a abertura à transcendência, as quais são geradas no interior da própria estrutura imanente. A religião, com suas festividades e rituais, permanece uma figura atual do Espírito, com ancoramento na experiência contemporânea, mais do que uma figura arcaica ainda hoje acessível.

O confronto entre Habermas e Taylor não é feito diretamente sobre a posição de Habermas em relação ao conjunto rito e mito, mas com as pressuposições que guiam a hipótese de precedência do rito sobre o mito como explicação da permanência de fonte religiosa arcaica, aberta aos que não optam pelos limites do pensamento secular. 


\section{RITO E MITO: QUAL TEM PRECEDÊNCIA?}

Antropólogos e sociólogos falam de "Religião" como um conjunto de crenças e práticas que pretendem assegurar forças salvíficas e afastar males a partir do contato com poderes extramundanos ou extraquotidianos. Habermas, conhecendo tais abordagens, pretende, porém, localizar as experiências do "Sagrado" no conjunto do desenvolvimento da humanidade, uma abordagem que poderíamos chamar de filogenética, para explicar como pode a religião se afirmar até hoje diante do quadro secular do Pensamento. Ele acolhe as reflexões de Karl Jaspers sobre o surgimento das grandes religiões no tempo-eixo, entre os anos de 800 a.C. e 200 a.C. Livros sagrados, tradições fortes, organização de comunidades de culto que moldaram civilizações datam desse período axial de revolucionamento do pensamento, que implicam em fundamentação do Mundo, em concepções morais universalizantes e novos conceitos de redenção e justiça.

Entretanto, pensa Habermas, tal movimento não pode ser visto apenas unilateralmente do ponto de vista intelectual, mas inclui rito e mito, narrativas e práticas simbólicas, amálgama que se mantém de modo transformado em novas condições culturais e que poderia explicar a continuidade da religião na sociedade ocidental, como veremos a seguir.

Os mitos, com sua flexível forma narrativa, são apropriados para a exposição do mundo como um todo organizado, enquanto no rito prevalece o aspecto performativo da execução de ações simbólicas esquemáticas. Porém ambos não devem ser vistos como simplesmente opostos. Se é aceitável que o mito possa ter surgido pela curiosidade de explicar o mundo, ele também, ao mesmo tempo, já agrega 
o esclarecimento das relações sociais nessa explicação, com isso tornando o estranho em algo familiar e então assegurando a identidade coletiva. A narrativa mítica é encenada periodicamente, ambos os níveis se inter-relacionam.

A práxis ritual tem o sentido, atribuído por nós, de superação de crises e, em primeiro lugar, da elaboração da consciência chocada com a finitude da existência humana. Ritos fúnebres, por exemplo, pretendem ajudar a lidar com a constatação, dificilmente compreensível e suportável, da necessidade de nos despedirmos das pessoas amadas e do mundo. A ideia de um espírito que sobrevive ao corpo sem vida e com o qual se pode entrar em contato faz a mediação entre a narração mítica e a invocação ritual.

Porém, pode-se levantar a questão mais geral: se mito e rito se desenvolveram ao mesmo tempo ou se o rito tem precedência. Prevalece nos mitos o aspecto de exposição do acontecer do mundo em forma gramatical de narrativa, buscando-se classificar fenômenos da natureza em cosmogonias e assim indicar a origem do mundo. De outro lado, sobressai nos ritos o aspecto performativo de execuções de ações esquematizadas e repetitivas, nas quais o conteúdo de significado se mantém implícito e símbolos e imagens entram em primeiro plano, como vínculo de interação.

Imagens do mundo têm, entretanto, uma impostação psicodinâmica, não apenas intelectual, mas prática. A mera contraposição de rito e mito não dá conta dessa relação. $\mathrm{O}$ próprio Lévi-Strauss (1971-1975 apud HABERMAS 2012, p. 81) explica o motivo dos mitos a partir de duas chaves. A primeira é a curiosidade intelectual, a busca de saber sobre o mundo. A segunda é a renovação da identidade coletiva. A imagem do mundo é articulada a partir das relações sociais do coletivo, então o Self coletivo se reencontra no mito e 
o estranho é assimilado ao familiar. Os riscos intramundanos são expostos e sua resolução é indicada através dos ritos, que não são apenas enunciação, mas ação. A repetição anual da narrativa mítica, como mostram pesquisas sobre festas do Ano Novo, devem assegurar a regularidade dos ritmos naturais e a estabilidade das relações sociais.

Antes da substituição de expressões linguísticas monossilábicas por uma linguagem gramaticalmente articulada, os ritos já expressavam performativamente um sentido, através de danças, músicas, pantomina, pintura do corpo. Um sentido de afastamento do mal e invocação do bem em diversos âmbitos da vida: superação de situações ameaçadoras como catástrofes, fome, epidemias, ou garantia das condições necessárias para a vida, tais como, chuva, colheita, saúde, etc. Tal sentido será expresso pelos mitos em linguagem proposicional.

O rito representa um nível mais antigo de comunicação e os significados nele encerrados devem ser buscados. Embora muitas interpretações, inclusive a de R. Girard, derivem os ritos a partir dos mitos, como modo de atrair a benevolência dos poderes sobre-humanos, Habermas não segue essa linha. Ele prefere aquela dos discípulos de Durkheim, H. Herbert e M. Mauss, (DURKHEIM 1981 apud HABERMAS 2012, p. 83) que dão a primazia a rituais elementares de presentes e de trocas, dos quais se poderiam mesmo ter originado os rituais de sacrifício. Talvez a partir da troca de mulheres, surgiram ritos que consolidavam relações de parentesco e de solidariedade através da troca de presentes. Rivais potenciais estabelecem vínculos rituais como Esaú e Jacó em Gênesis, 33. Durkheim vê o rito como estabilizador das conexões sociais, com um sentido próprio, independente das conexões narra- 
tivas. Ele investiga as práticas rituais sob dois pontos de vista: autotematização da sociedade e produção da força normativa das regras de interação.

As investigações de Van Gennep (1986 apud HABERMAS, 2012, p. 84) sobre ritos de iniciação complementam Durkheim sob um importante aspecto. Ele investiga os ritos de passagem, onde os candidatos a um novo status aprendem as novas prescrições e adquirem disposições para cumpri-las. No caso da iniciação de adultos, o rito faz frente à ameaça de descontinuidade entre gerações e de enfraquecimento do vínculo social. Gennep ressalta um momento especial da iniciação, que é o isolamento do candidato, no processo de morte e ressurreição. Isso traz à consciência do iniciando não apenas as novas habilidades a serem conquistadas, mas a sua dependência do coletivo. Ele só pode adquirir a nova identidade morrendo para a antiga, autoabandonando-se.

Para muitos pesquisadores o rito é uma linguagem autônoma, que assegura a coesão grupal. Além disso, outros desenvolvem o aspecto de tratamento das questões de sentido último: nascimento, morte, fragilidade da vida comum, vulnerabilidade do corpo e da alma. Habermas menciona essas questões antropológicas e existenciais, procurando mostrar como o rito busca resposta para elas, pretendendo não precisar se pronunciar sobre a racionalidade das respostas teoricamente articuladas nos mitos e religiões, sem considerar tais respostas como racionalmente constitutivas para um sentido universal do homem e do coletivo no mundo. 


\section{PARA QUAL PROBLEMA O RITO SE APRESENTA COMO SOLUÇÃO?}

Habermas começa a traçar uma hipótese para explicar o surgimento do rito como solução de problemas surgidos em um certo momento da evolução da comunicação, precisamente aquele na passagem entre a comunicação por gestos e a comunicação por símbolos (LUCHI 1999, 231ss). Em ambos os casos temos que a comunicação se dá através de imitação e de apresentação icônica, mas no primeiro caso em meio ao quotidiano da vida e no segundo para além do quotidiano.

Os mecanismos naturais da evolução, a saber, mutação e seleção natural, com o aprendizado da fala pela espécie humana, cedem lugar a processos culturais de aprendizado. No âmbito da linguagem gestual e simbólica, as pretensões de validade inseridas na linguagem estão ainda indiferenciadas. Com a ajuda de Tomasello (2002 apud HABERMAS 2012, p. 87), torna-se claro que uma diferença entre as capacidades das crias de chipanzés e das crianças humanas se dá no nível da capacidade de cooperação para atingir fins objetivos no mundo, que não sejam apenas igualmente orientados, mas também compartilhados.

Com efeito, também primatas fazem a passagem de uma comunicação baseada em gestos para o uso de símbolos que assumem o mesmo significado para os membros do grupo. Somente que eles não rompem a barreira da autorreferência, a qual procura realizar individualmente certos objetivos próprios, em direção a uma visão intersubjetivamente compartilhada, eles permanecem no nível da realização de fins estratégicos, onde um é capaz de manipular o outro, mas não podem entrar numa relação 
interpessoal de cooperação, ou seja, para atingir cooperativamente um fim comum no mundo objetivo, como seria uma caçada em comum.

Em geral, pode-se dizer que se comunicar é "entender-se mutuamente sobre algo no mundo". No nível de comunicação através de gestos já há intercâmbio de conteúdos semânticos, porém de forma ainda não diferenciada. Expressões monossilábicas e gestos como "fogo!" englobam: a) a indicação de acontecimentos no mundo; b) sua repercussão afetiva sobre quem fala; c) apelos dirigidos a outros. Mas no caso dos chipanzés tal intercâmbio gestual não implica a instituição de um espaço simbólico comum, ou de significações compartilhadas, porque para isso seriam necessárias: a) a produção de uma relação interpessoal entre Ego e Alter, pela assunção da perspectiva do outro; b) a realização da intenção comunicativa se dando a partir de uma relação compartilhada no mundo objetivo, de tal modo que somente assim o mundo seria idêntico e independente.

A especificidade humana dessas duas realizações acima mencionadas se pode documentar pela constatação que: a) macacos não se olham nos olhos, saudando-se: não são, então, uns para os outros uma segunda pessoa; b) macacos não fazem pantomina, quer dizer, não chamam a atenção de seus companheiros de espécie para algo no mundo a ser interpretado compartilhadamente.

Segundo as pesquisas de Tomasello, a relação tríplice a algo no mundo, indicativa, afetiva e apelativa, é algo característico dos homens e não ainda dos primatas. Por mais inteligentes que sejam os chipanzés, eles somente se dirigem aos companheiros para fins imperativos, para manipulá-los para seus fins, de sexo ou cuidado do corpo por exemplo. Não comentam algo no mundo. 
Habermas considera que pressões cognitivas e cooperativas impulsionam a evolução social, provocando um desequilíbrio entre a integração na vida do coletivo social e a afirmação da identidade. A urgência da reequilibração, de onde se devem haurir forças motivadoras para engajamento individualizado no coletivo, é respondida pelo rito, que é então "autorreferente", isto é, não se dirige a algo objetivo no mundo, mas à renovação da força motivadora da normatividade coletiva. "Eu entendo o rito como uma variante da comunicação gestual; também ele é uma forma mimética de comunicação que produz um mundo de significados simbólicos" (HABERMAS 2012, p. 91). Que a autorreferência seja uma característica do rito significa que ele não se refere a algo no mundo identificado por todos, mas procura responder a perturbações surgidas no interior do coletivo social.

A inicial comunicação por gestos é exposta à crise, num primeiro aspecto do ponto de vista cognitivo, porque a avalanche de informações sobre o mundo precisa ser elaborada e, então, integrada nos parâmetros dados. Também no patamar da linguagem proposicionalmente diferenciada, o volume de informações sobre o acontecer do mundo pressiona para a elaboração de uma imagem mítica do mundo, como acena Levi-Strauss, algo análogo às ciências, por exemplo, nas cosmogonias.

O desafio evolucionário, porém, não ocorre apenas no nível cognitivo, mas também social. Desde os primeiros níveis, onde se dava uma resposta a apelos de um indivíduo através de signale manifestados estrategicamente e que permaneciam egocêntricos até a urgência para uma cooperação que articula respostas às contingências do mundo, é necessária uma transformação revolucionária da integração 
social. Podemos falar aqui de uma adaptação para a cooperação. Essa revolução vem junto com uma dupla pressão: quanto mais o ônus da coordenação de ações cai sobre o agir comunicativo os indivíduos se apercebem ao mesmo tempo como dependentes do espírito objetivo e como consciência individual. $O$ poder do coletivo se mostra como ambiente de garantia da sobrevivência e segurança, o qual, ao mesmo tempo, precisa ser delimitado em relação à individualidade.

Aqui a explicação do Rito:

A Normatividade que é ganha por uma tal força reguladora da ação vai além da normatividade, inerente ela mesma à comunicação, do uso de símbolos obediente a convenções. Quando nós procuramos um gerador para essa normatividade forte, que vincula os motivos da ação, o comportamento ritual se apresenta como uma fonte plausível da história natural (HABERMAS 2012, p. 93).

Então, diante das crises motivacionais supraindicadas, quer dizer, diante do desafio de haurir motivos, forças subjetivas de envolvimento com as normas sociais, para equilibrar ao mesmo tempo a pertença a um todo social e a identidade própria, a práxis ritual oferece uma fonte de renovação das motivações para a pertença aceitadora e observante das normas sociais. No rito, os membros renovam e aprofundam sua dependência do poderoso coletivo. Os conceitos durkheimianos de abordagem das práticas rituais, a saber, "regeneração da solidariedade social" e "autotematização da sociedade" ajudam Habermas na sua leitura das origens do "complexo sacral", rito e mito.

A evolução das formas de comunicação e do processo de socialização traz embutidas crises estruturais para as quais o rito se apresenta como fonte de reequilibração. $\mathrm{O}$ rito não se remete a algo no mundo objetual. 
Segundo minha sugestão essa crise remonta, do ponto de vista da história do gênero, à adaptação da cognição e coordenação de ações do nível de comunicação pré-linguística a linguística, onde a socialização da inteligência vai mão a mão com uma socialização individualizante dos sujeitos agentes (HABERMAS 2012, p. 93).

Habermas não menciona, nesse contexto, outro tipo de crise ao qual o rito poderia responder; a crise existencial pelo sentido e a busca de soluções para problemas concretos no mundo. Ritos para fazer chover, para curar doenças, então não entram na definição de ritos para Habermas? A renovação da pertença ao todo coletivo não se esgota no próprio grupo social, mas pode se ancorar numa instância transcendente e estar vinculada à busca de condições materiais de sobrevivência.

\section{UMA EXPERIÊNCIA ARCAICA SOMENTE ACESSÍVEL A PESSOAS RELIGIOSAS}

A práxis ritual promove a renovação da solidariedade de um grupo social cuja vinculação é sujeita a perturbações e crises. Nessa linha, Habermas busca também uma explicação para as transformações do complexo sacral, isto é, para a vinculação entre mito e rito, em suas diversas concretizações.

Seja que tenham surgido independente dos ritos seja que somente decifrem seu sentido, mitos preenchem a função de explicar o mundo cognitivamente, de tornar o conjunto, apreensível a cada momento, do acontecer do mundo, possível de compreensão unificante. Porém, por isso mesmo, mitos estão sujeitos a experiências conflitantes, em vista do choque com os novos dados do saber profano do mundo. Então eles não conseguem assegurar sozinhos a identidade do grupo nem do indivíduo a partir de uma in- 
terpretação do mundo.

O entrelaçamento do mito e do rito foi funcional para a identidade e a solidariedade social porque complementa um modo não narrativo de tais realizações. A longo prazo as explicações míticas do mundo se mostram incompatíveis com a ciência e se desclassificam como capazes de assegurar a identidade. De fato, as religiões mundiais, superando o pensamento mágico e o sacrifício, retiram o fundamento do mito, sendo apenas possível um novo arranjo do pensamento religioso metafísico com as ciências institucionalizadas e com o Estado secularizado.

De outro lado, a práxis ritual foi mantida, mesmo que de modo transformado:

O complexo sacral não se dissolveu; tradições religiosas conservaram sua vitalidade em simbiose com o culto de suas comunidades. Os membros das comunidades religiosas podem até mesmo reclamar para si o privilégio de ter conservado, na realização das práticas cúlticas, o acesso a uma experiência arcaica - e o acesso a uma fonte de solidariedade - que se fechou aos filhos e filhas não crentes da modernidade (HABERMAS 2012, p. 95).

Quer dizer, o elemento mais decisivo e fundamental do complexo sacral é o rito e não o mito. Enquanto o mito está fadado ao desaparecimento como explicação do mundo, com o advento das ciências modernas, o rito conserva sua capacidade de renovação da solidariedade, mesmo que continue a ser considerado uma "experiência arcaica".

\section{TAYLOR: UMA ORDEM IMANENTE POSSIVELMENTE ABERTA À TRANSCENDÊNCIA}

A secularização moderna foi acompanhada do desenvolvimento de uma "identidade protegida": o Eu não mais vulnerável a forças cósmicas, como era o anterior Eu poro- 
so. Mente e mundo são agora separados e ocorreu um processo de interiorização (TAYLOR 2010, p. 634) . As profundezas antes cósmicas agora são localizadas no nosso interior.

O Eu protegido e sua interioridade foram sendo dotados de uma disciplina e autocontrole, sobretudo nos âmbitos da sexualidade e da ira. Desenvolveu-se também a privacidade, espaços seletivos de intimidade para ações que antes eram realizadas em contatos mais promíscuos: alimentação, higiene pessoal, partos, etc. Hábitos de interioridade, de sua exploração e explicitação, são agora aprendidos e manifestos através de cartas, romances, orações, diálogos.

As ordens sociais modernas não possuem fundamento cósmico anterior, os lugares que os seres humanos ocupam não correspondem a algo pré-estabelecido, mas decorrem das razões de associações e concorrem simplesmente para o bem, acentuando a individualidade. A Reforma religiosa incentivou e reforçou a conexão de proteção, disciplina e individualidade, com sua prática de vida religiosa mais pessoal, comprometida, não mais focada no ritual coletivo. As concepções holísticas mais antigas se tornaram quase incompreensíveis. Cada um é convocado a assumir sua responsabilidade social e religiosa, não podendo se contentar mais com ser apenas um membro do grupo.

A deslegitimação das monarquias tradicionais com base na ordem cósmica fez parte também desse processo de desencantamento assim como a passagem da experiência de um tempo superior para o tempo secular, do qual então temos que tirar a máxima vantagem. A racionalidade instrumental vai se impondo.

Assim sendo, a identidade protegida do indivíduo disciplinado se move num espaço social construído, onde a racionalidade instru- 
mental é o valor-chave e o tempo é impregnantemente secular. Tudo isso perfaz o que eu gostaria de chamar de 'a estrutura imanente' (TAYLOR 2010, p. 636).

Essas ideias que constituem a estrutura imanente, marcantes de nossa autocompreensão prática, encaixam-se muito bem com a ciência pós-galileana, principal mudança teórica da modernidade. $\mathrm{O}$ universo físico é governado por leis que não admitem exceções e, para serem entendidas não é preciso, num primeiro plano, qualquer referência a um Bem visado, às Ideias platônicas ou à mente de Deus. Embora não seja tampouco necessário negar que tais leis possam refletir a sabedoria de um criador.

A ciência moderna dispensou a referência a intervenções vindas de fora e favoreceu uma postura instrumental, do alcance de resultados. A nova compreensão da sociedade fez emergir a noção de agentes coletivos como também a auto-objetivação da sociedade, vista como governada por leis próprias. Assim, as ordens cósmica, social e moral passam a ser consideradas como autossuficientes e seu processo histórico como processo de maturação.

As ordens sociais que inicialmente se descolaram de uma base religiosa passam a ser vistas como Natureza, inicialmente refletindo o projeto de Deus, depois independente de Deus para finalmente serem colocadas completamente nas mãos da motivação humana. A ordem imanente assim surgida pode descartar a transcendência, porém não necessariamente. Nós ocidentais modernos vivemos nessa ordem imanente, alguns a vivenciam como fechada outros como aberta a algo além dela.

Taylor tenta mapear possibilidades de abertura ao transcendente. Um primeiro caminho é aquele da adoção de "avaliações fortes" que vinculam o mais elevado a Deus 
(TAYLOR 2010, p. 638). Quando admitimos "avaliações fortes", distinguimos o vício da virtude, o elevado do vil, o bem do mal, de tal modo que a quantidade acumulada do que é "baixo" não resulta no mais elevado. Onde tais avaliações fortes estão vinculadas a Deus ou a algo transcendente, funda-se uma fé nesse mais elevado. Esse senso foi desenvolvido em contato com vidas heroicas de santidade, momentos de oração ou de audição de música sacra, por exemplo. Sem referência a Deus, tais pessoas não poderiam dar sentido a essa experiência de elevação moral e existencial.

Experiências posteriores podem levar a alguma mudança, de tal modo que possam até compreender o que seria uma moral sem Deus. Ou podem fazer negar a postura da imanência. Conversões que reforçam o apelo a Deus para viver a disciplina produtiva são um exemplo. As atuais ondas de pentecostalismo são experiências atuais de conversão. Os islamistas negros são uma forma extra-cristã de tais conversões.

Tais retornos religiosos à transcendência podem ser também significativos para a identidade coletiva e não apenas individual, fala-se então de uma nação sob Deus, um grupo étnico que se entende numa relação substancial com Deus. Essa experiência de transcendência pode ser vivida positivamente, como no caso da construção de identidades coletivas, ou negativamente, como algo pelo qual ansiamos. Num quadro de utilitarismo emerge a interrogação "isso é tudo que há?" (TAYLOR 2010, p. 640). Sente-se a falta da afirmação de heroísmo, da dedicação à humanidade até o sacrifício, de uma integração com o universo. Pode haver mesmo irrupção de elementos reprimidos, em eventos celebrativos ou festivos. 
Podemos delinear uma tríplice reação ao utilitarismo: a) permanecendo nos limites das ciências naturais e sociais, radicaliza-se e amplia-se a noção de bem como em Rousseau e Marx; b) afirmação de imanência que rejeita o ideal de igualdade, exaltando formas elevadas de vida para a minoria, assim para o contra-iluminismo imanente; e c) reconhecimento da transcendência.

Taylor dedica muitas páginas para mostrar que o fechamento da estrutura imanente, a exclusão do transcendente não é simplesmente óbvia e que, portanto, modernidade não é sinônimo de eliminação da religião (TAYLOR 2010, p. 652ss). Passamos por mudanças no sentido da estrutura que vivemos, bem como no nosso imaginário sobre ela. As molduras científica, social, tecnológica constituem uma ordem natural que pode ser entendida por si mesma, sem referência ao sobrenatural. Sua tese soa:

Porém essa ordem por si mesma deixa em aberto a questão se, em função de uma explicação última ou da transformação espiritual ou da atribuição última de sentido, teremos de invocar algo transcendente. Somente quando a ordem é 'volteada' em determinado sentido ela parece ditar uma interpretação fechada (TAYLOR 2010, p. 697).

Formas de vida religiosa tornadas insustentáveis foram substituídas por outras, num processo continuado e personalizado; as pessoas se posicionam diferentemente em relação à religião, ao longo da vida, numa permanente instabilidade. Embora haja também declínio da crença, diferenciado por sociedade, a característica mais geral é a "mútua fragilização de posições religiosas diferentes" (TAYLOR 2010, p. 698) e da descrença. A atração de narrativas da imanência fechadas é contra pressionada pela sua 
insuficiência, por ambientes religiosos e por insinuações da transcendência.

O materialismo que reduz motivações e desejos a mecanismos naturais é experimentado como estreito demais. A admissão de motivações apenas baixas e não de ideais morais permanece no nível dos impulsos emocionais. As diversas versões do fechamento materialista são contestadas por uma visão do que seja a plenitude da vida humana: a) não somos completamente determinados, mas criativos e construtivos; b) temos motivos éticos mais elevados, por exemplo, o respeito à lei moral; c) temos uma noção mais profunda de significado, nossa experiência estética não se reduz ao prazer.

Claro que muitos materialistas sustentam uma ética elevada. Mas permanece a pergunta: "Como justificar a força específica da atividade criativa ou das demandas éticas ou o poder da experiência artística sem falar em termos de algum ser ou força transcendente que nos interpela?" (TAYLOR 2010, p. 700).

\section{ELEMENTOS DO DEBATE ENTRE HABERMAS E TAYLOR}

Habermas replica diversas objeções a suas posições filosófico-religiosas. As considerações sobre Casanova serão úteis para compreender o contexto de observações sobre Taylor. Casanova pensa poder explicar mudanças religiosas com situações socioculturais mudadas, enquanto Habermas não considera esse ponto de vista suficiente, mas vê cambiamentos religiosos epocais como melhor esclarecidos no quadro de um processo de aprendizado histórico-evolutivo (CASANOVA 2009 apud HABERMAS, 2012, pp. 122ss).

$\mathrm{Na}$ passagem das sociedades tribais (3000 a.C.) para so- 
ciedades estatalmente organizadas houve mudanças dos rituais para que agora se favorecesse o domínio do governante estatal, bem como das narrativas míticas, que passavam a espelhar a centralização do poder político. Mas isso nada mudou "na estrutura cognitiva das imagens do mundo" nem no pensamento mágico.

Somente na metade do primeiro milênio antes de Cristo formaram-se imagens metafísicas do mundo e religiões mundiais que alcançaram um ponto de vista transcendental extramundano. Deuses arbitrários guiados por seu humor não mais satisfazem a nova sensibilidade moral de profetas e monges. Além disso, o saber natural-científico acumulado - astronomia, medicina, matemática - devia entrar em conflito com práticas mágicas. Conforme Girard ocorre uma transignificação ética dos ritos transmitidos e abolição dos sacrifícios (GIRARD 2002 apud HABERMAS, 2012, p.124).

Podemos indicar duas diferenças entre Filosofia e Tradições religiosas: a) um outro modo e outra base de justificação do tomar por verdadeiro; b) no caso da religião, "ancoramento estabilizante da fé nas práticas cúlticas de uma comunidade de fé". No quadro do diálogo com Casanova, seu interlocutor pensa que "a mudança estrutural das imagens religiosas do mundo e das correspondentes práticas rituais não podem ser explicadas somente com adaptações a ambientes sociais modificados" (HABERMAS 2012, pp 122-123).

Habermas critica Casanova quanto à expressão: "O sagrado cristão era o profano pagão e vice-versa" porque; a) havia entre os romanos o "terceiro partido" das pessoas cultas: estoicos, epicuristas, neoplatônicos; b) a expressão sugere simetria entre paganismo e cristianismo, quando de 
fato o cristianismo não apenas rejeita o politeísmo, mas uma maneira de pensar concretística, presa ao acontecer mundano. Há algo na mensagem cristã que não é somente adaptação a novas condições sociais da fé, mas um salto de qualidade.

Uma observação irônica de Habermas revela sua defesa da superioridade do pensamento secular. Foram os cristãos que se sentiram superiores aos pagãos, introduzindo a consciência de níveis de desenvolvimento religiosos. Hoje os cidadãos não-religiosos podem ser vistos como manifestando algo dessa consciência superior. Mesmo o questionamento de tal pretensão não deve negar níveis de consciência religiosa, enfatiza ele.

A modernidade, do ponto de vista religioso, marcou uma cesura semelhante àquela do tempo-eixo anterior. A igreja e a teologia, na alta idade média, desencadearam movimentos jurídicos e epistêmicos que fugiram ao seu controle e explodiram o Direito natural cristão como também a filosofia da natureza aristotélica. (HABERMAS 2012, p. 125). Os modos profanos do saber jurídico e das ciências naturais, que foram se impondo, retroagiram sobre suas raízes teológicas. Houve mudanças tanto na teologia como na filosofia.

A consciência religiosa que se "reformou" (num sentido não confessional) e o pensar pós-metafísico que elabora uma crítica da razão (em duplo sentido) sem se tornar derrotista, são no fim respostas complementares ao mesmo desafio cognitivo do Iluminismo alimentado de fontes seculares do saber (HABERMAS 2012, p. 126).

Contra uma desvalorização secularista da religião, a teologia pode se entender legitimamente como intérprete da autocompreensão de uma comunidade de fé vivente no seu culto. A comunidade de fé "mantém a ligação a uma fonte 
arcaica de solidariedade social, à qual o pensar secular não tem mais acesso [...] para nós, espíritos seculares, somente a experiência estética ainda contém elementos vestigiais dessa fonte amplamente fechada" (HABERMAS 2012, p. 126).

Então a experiência estética se alimenta também dessa fonte arcaica de solidariedade social, a única acessível aos "espíritos seculares", não abertos aos ritos religiosos. Porém somente o pensamento pós-metafísico se movimenta no espaço aberto a todos do mesmo modo. Quer dizer, fonte de solidariedade universalmente acessível a todos seria apenas a argumentação comunicativa. As outras duas fontes são arcaicas, uma acessível aos espíritos seculares, a experiência estética, e outra somente aos espíritos religiosos.

Mais especificamente ao aspecto da atualidade da religião como capaz de fornecer recursos para terapia e reconstrução de identidades pessoais feridas, Habermas acena (HABERMAS 2012, p. 88) para uma breve observação sobre a arte, agora também estendida a aspectos mais sociais. Artistas seriam espíritos com especial sensibilidade para seu momento histórico e, nesse quadro, fazem experiência de "climas afetivos sublimes" a qual pode ser comunicada, porém seu conteúdo não se esgota em proposições linguísticas e precisa ser transmitido também através de meios não proposicionais. $\mathrm{Na}$ obra de arte entrelaçam-se componentes proposicionais, expressivos e apelativos, não traduziveis completamente em proposições, algo semelhante ao rito.

Poderíamos aproximar Religião e Arte, concluindo que também na Religião espíritos sensíveis às vibrações culturais de momentos históricos fazem experiência de sentido e de outro clima afetivo que pode ser expresso proposicionalmente somente em parte, precisando também ser 
exteriorizadas com meios não proposicionais, que irão plasmar os próprios rituais.

A crítica de Habermas a Taylor nesse contexto é explícita:

Esse pensamento pós-metafísico assim entendido não se amolda àquela imagem, pintada de modo fenomenologicamente rico, da compreensão do mundo e do Self sem transcendência, que Charles Taylor desenha sob o título de immanent frame, todavia muito fraco em relação à filosofia (HABERMAS 2012, p.127).

Quer dizer, pelo que também na sequência do texto de Habermas fica claro, o imperativo moral de origem kantiana, mesmo comunicativamente reformulado, contém uma transcendência a partir do interno, capaz de ultrapassar a particularidade e o contexto local. Em outras palavras, Taylor concederia pouca força de superação ao quadro imanente do $\mathrm{Eu}$, que em consequência deve apelar para uma transcendência a partir de fora, para colocar o Self em condições de aderir exigentemente a uma elevação moral para além de si mesmo. Habermas compreende os processos de comunicação como dotados já internamente de uma força de transcendência em direção ao melhor argumento e à universalidade, que não convence Taylor. Implementar condições contrárias aos próprios interesses exige uma força moral e uma busca de plenitude que, para a maior parte das pessoas, vai junto com a abertura à transcendência "de fora”.

Já num artigo de 1986, Taylor (1986, 35ss; LUCHI 1999, 362ss) acenava para a insuficiência do formalismo da proposta comunicativa de Habermas, que não é capaz de oferecer razões para a busca nem para a implementação do melhor argumento e tampouco responderia à questão das "valorações fortes" da vida humana. Taylor pensa que o 
próprio Kant, com a doutrina do Sumo Bem, teria retornado a uma perspectiva substancial. Recentemente, no quadro de um debate entre ambos, Taylor reafirma sua posição, referindo-se à postulação de Habermas de uma necessária tradução de termos religiosos em seculares, no âmbito político:

A diferenciação entre discurso religioso e não religioso seria mais plausível se houvesse uma fundamentação "secular" impermeável, por exemplo, para o direito à Vida. E precisamente nesse ponto separamo-nos, Habermas e eu. Ele encontra tal fundamentação confiável na ética do Discurso, que infelizmente não pode me convencer (MENDIETA; VANANTWERPEN 2012, p. 82).

Quanto à observação de Habermas de que a narrativa Tayloriana seria fenomenologicamente rica, mas filosoficamente fraca, podemos dizer que, de um lado, é verdade que Taylor não argumenta de modo estringente e conciso, sua narrativa, porém, poderia ser entendida como terapêutica, como sugere Goldstein (2011). Ele diagnostica os riscos de uma modernidade que promove um autoencapsulamento patológico do Self utilitaristicamente asfixiado e conduz à falta de sentido, tornando frágil tudo o que seria valioso para nós, mesmo reconhecendo os ganhos de virada moderna. Sua narrativa pretende iluminar o caminho que nos trouxe até aqui, para podermos nos reorientar moral e existencialmente, libertando-nos de certezas confortáveis que identificam modernização com total rejeição da religião. Seu horizonte de interpretação não são as elites de sábios, mas as massas.

\section{CONSIDERAÇÕES CONCLUSIVAS}

A afirmação de Habermas de que os cidadãos religiosos 
conservam acesso a uma experiência arcaica, acesso perdido para os filhos da modernidade, permanece ambígua: pode indicar que a modernidade perdeu uma fonte de solidariedade e que a religião continua válida como complemento para o recurso solidariedade, porém ao preço de ser considerada como algo arcaico. A religião comparece como algo ainda valorizável diante dos descaminhos fáticos da modernidade, porém por si mesma seria incompatível com o mundo moderno. Não seria mais dotada de racionalidade cognitiva, mas apenas de valor pragmático, até quando não se sabe. A não ser que o próprio conceito de modernidade em Habermas e a legitimidade de sua expansão implementativa deva ser repensado.

Com efeito, um número crescente de pensadores perfaz uma desvinculação teórica entre modernidade e secularização. Quer dizer, não é mais plausível a identificação entre processos modernos de desencantamento e autonomia, de um lado, e abandono da religião, do outro, de tal modo que ela pudesse ser considerada um resquício do passado. É o caso de Jose Casanova, Hans Jonas e Charles Taylor, para citar alguns. Habermas manifesta dificuldade de mudar de posicionamento, suas recentes investigações mostram avanços em relação à religião, mas lhe atribuem status estético de uma opção facultativa de sentido do todo, na esfera do "como se" (LUCHI; CAVALIERI 2014).

A permanência da prática religiosa no mundo ocidental contemporâneo e mesmo sua tendência a crescimento tem análises muito diferentes em Habermas e Taylor, que, entretanto, movem-se num quadro sociológico semelhante. Enquanto Habermas busca uma explicação ancorada no passado ritual, que ainda não teria esgotado seus recursos para a sociedade e a pessoa, Taylor vê bases para a conti- 
nuidade da religião nas próprias práticas sociais contemporâneas. Ele faz um esforço teórico para desidentificar modernização com secularização. A transcendência continua a se insinuar para o mundo ocidental e permanece uma opção aberta, com fundamentação, é a posição de Taylor. Ele não entende como Habermas a transcendência somente a partir de dentro da estrutura da comunicação, como uma idealização de condições ideais de argumentação, mas como Bem, como Plenitude, poderoso e irrenunciável estímulo, socialmente falando, a um ultrapassamento do quadro da mera individualidade e seus interesses.

Habermas, em debate com Taylor, deixa claro que, em um nível mais amplo, considera a religião como produção do espírito humano tão digna quanto a ciência (MENDIETA; VANANTWERPEN 2012, p. 90). Porém a divergência é a consideração de quais razões podem ser admitidas imediatamente no âmbito público, no nosso contexto pluralista pós-secular. Taylor admite aí também razões religiosas e exemplifica com Luther King, cujas palavras e imagens todos podiam entender. Habermas exige tradução da linguagem religiosa para a secular.

No quadro geral da teoria de Habermas, a permanência e revitalização de grupos religiosos podem ser associadas à colonização do mundo da vida pelo mercado e o correspondente esgotamento dos recursos de solidariedade, quadro em que as pessoas tenderiam a buscar outras fontes de integração e identificação, bem como de terapia para suas feridas, pelo menos em parte decorrentes também das patologias sociais, isto é, tenderiam a recorrer a fontes religiosas e estéticas. Habermas permanece, portanto, num quadro funcional. Taylor vai além dessa delimitação, certamente reconhecendo feridas e insuficiências da "ordem 
imanente", com suas tendências redutoras, mas atribuindo à transcendência valor positivo insubstituível para a vida humana em geral, e isso é traduzido e impostado para as condições sociais contemporâneas.

Tanto Habermas como Taylor acentuam que não podemos ignorar que vivemos em condições modernas de autonomia da ciência e pluralismo de mentalidades. Tratase de uma estrutura imanente. O lugar da religião nesse contexto é expresso diversamente. Para Habermas o acesso a uma experiência ritual arcaica que desperta e reforça energias de vinculação social, uma explicação que permanece no quadro da imanência, que, porém, é visto como já contendo em si o aguilhão de seu ultrapassamento, uma transcendência a partir de dentro. Taylor vê positivamente a possibilidade de abertura à transcendência, não só constata essa opção, mas afirma sua racionalidade e efeitos construtivos.

Revalorizando as práticas rituais como lócus privilegiado de fonte de força afirmativa das religiões e reconduzindo-as à normatividade coletiva, de certa forma Habermas perfaz um caminho análogo àquele de Kant a Hegel, no que diz respeito à investigação da religião, enquanto faz uma passagem da ética ao culto. Porém, cala-se sobre a relevância da busca de um sentido enquanto Unidade do Todo, Origem e Telos de tudo, Logos do Universo, como se tal busca metafísica representasse uma etapa completamente ultrapassada de validade racional.

O ponto de partida de Habermas para compreender o rito é desde o início recortado: a necessidade de renovação da coesão de um grupo social. Porém poderíamos também perguntar: por que tal necessidade, por que cada indivíduo precisa se remeter ao todo coletivo e é capaz também de ir 
além de seu coletivo? As crenças que o rito pressupõe e promove seriam sem interesse diante da função de realimentação da solidariedade, com meios arcaicos, em tempos de crise e escassez? O vetor metafísico de conhecimento da Verdade do todo seria então sem significado, importando apenas os dois outros âmbitos dos recursos de solidariedade - Sociedade - e de subsídios terapêuticos - Personalidade? O remetimento a uma fonte transcendental de justiça e universalidade, que as grandes religiões mundiais perfazem não me parece poder simplesmente ser aplainado como epifenômeno de significados, ou parasita teórico.

As celebrações religiosas e as festividades são vistas por Taylor como uma possível fonte de sentido, uma experiência de inserção na totalidade que corresponde a um anseio contestador da fragmentação individualista e utilitarista da sociedade contemporânea. Não seria então apenas uma experiência arcaica, mas atualmente relevante e acessível ao homem de hoje, que dela necessita para uma abertura de horizontes e onde se insinua a transcendência.

De que depende o efetivo acesso das pessoas à experiência religiosa? Em Habermas, de uma certa sensibilidade próxima da estética, que não se inclui em exigências racionais universais. Taylor constata a possível abertura ou fechamento das pessoas à transcendência, mas tende a mostrar que a abertura é o caminho mais consequente e enriquecedor, que tem fundamentos e motivações não apenas estéticas, mas também até mesmo cognitivas. A transcendência religiosa é fonte de elevação moral para grande parte das pessoas, a sede do infinito está latente em todo homem e pode se manifestar como estímulo para a construção de identidade e para o florescimento humano.

Abstract: This article reconstructs Habermas' hypothesis that in the sacred PHILÓSOPHOS, GOIÂNIA, V.20, N.2, P.81-109, JUL./DEZ. 2015. 
system rite precedes myth and that could explain the permanence of religion as an archaic source of solidarity even in the context of the secular world. Mythical narratives, in confrontation with science, are losing capacity to explain the world, while religious rites are still able to produce social integration and to collaborate for the construction of identities, at least for those who manifest such sensibility. Confrontation is established with Charles Taylor's positions, not directly about the hypothesis mentioned above but about the assumptions that inspire it. Taylor sees religious experience as generated in the present, an opening to transcendence from the internal of the modern immanent order, capable to offer therapy to pathologies of a modernity that, although has accomplished great advances, has the risk of selfencapsulation.

Keywords: Rites; myths; social solidarity; individualization.

\section{REFERÊNCIAS}

CASANOVA, J. Europas Angst vor der Religion. Berlin: Berlin Univ. Press, 2009.

DURKHEIM, E. Die elementaren Formen des religioesen Lebens. Frankfut am Main: Suhrkamp, 1981.

GIRARD, R. Ich sah den Satan vom Himmel fallen wie einen Blitz. Eine kritische Apologie des Christentums. Muenchen: Carl Hanser, 2002.

GOLDSTEIN, J. Saekularisierung als Versehung. Charles Taylor Erzaehlung der Moderne In: KUEHNLEIN, M. und LUTZ-BACHMANN, M. Unerfuellte Moderne? Neue Perspectiven auf das Werk von Charles Taylor. Frankfurt am Main: Suhrkamp, 2011. p. 623-649.

HABERMAS, J. Nachmetaphysisches Denken II. Aufsaetze und Repliken. Frankfurt am Main: Suhrkamp, 2012.

LEVI-STRAUSS, C. Mythologica I-IV. Frankfurt am Main: Suhkamp, 1971-1975. 
LUCHI, J. P. A superação da filosofia da Consciência em J. Habermas. Roma: Ed. PUG, 1999.

LUCHI, J.P.; CAVALIERI, E. A filosofia kantiana da religião lida em chave agnóstica por J. Habermas In: Problemata: Revista Internacional de Filosofia, v. 5, n 2, p. 44-67, 2014.

MENDIETA, E.; VanAntwerpen, J. Religion und Oeffentlichkeit. Frankfurt am Main: Suhrkamp, 2012.

TAYLOR, Ch. Sprache und Gesellschaft In: HONNETH, A. UND JOAS, H. Kommunikatives Handeln. Frankfurt am Main: Suhrkamp, 1986.

2010.

- Uma Era secular. São Leopoldo: Ed. Unisinos,

TOMASELLO, M. Die kulturelle Entwicklung des menschlichen Denkens. Frankfurt am Main: Suhrkamp, 2002.

VAN GENNEP, A. Uebergangsriten. Frankfurt am Main: Campus, 1986. 